Keywords: colorectal liver metastases; colorectal cancer; cetuximab; epidermal growth factor inhibition; chemotherapy; liver resection; progressive disease; cancer research UK

\title{
Patterns of progression, treatment of progressive disease and post-progression survival in the New EPOC study
}

Siân A Pugh ${ }^{*}, 1$, Megan Bowers ${ }^{2}$, Alexandre Ball ${ }^{3}$, Stephen Falk ${ }^{4}$, Meg Finch-Jones ${ }^{4,5}$, Juan W Valle ${ }^{6}$, Derek A O'Reilly ${ }^{7,8}$, Ajith K Siriwardena9, Joanne Hornbuckle ${ }^{10}$, Myrddin Rees ${ }^{11}$, Charlotte Rees ${ }^{12}$, Tim Iveson ${ }^{13}$, Tamas Hickish ${ }^{14,15}$, Tom Maishman ${ }^{2}$, Louise Stanton ${ }^{2}$, Elizabeth Dixon ${ }^{2}$, Andrea Corkhill ${ }^{2}$, Mike Radford ${ }^{2}$, O James Garden ${ }^{16}$, David Cunningham ${ }^{17}$, Tim S Maughan ${ }^{18}$, John A Bridgewater ${ }^{19}$ and John N Primrose ${ }^{1}$

${ }^{1}$ University Surgery and Cancer Sciences Division, University of Southampton, Southampton General Hospital, Southampton SO16 6YD, UK; ${ }^{2}$ Southampton Clinical Trials Unit, Southampton, UK; ${ }^{3}$ Royal Bournemouth Hospital, Bournemouth, UK; ${ }^{4}$ Bristol Cancer Institute, University Hospitals Bristol NHS Foundation Trust, Bristol, UK; ${ }^{5}$ Department of Upper Gastrointestinal Surgery, University Hospitals Bristol NHS Foundation Trust, Bristol, UK; ${ }^{6}$ University of Manchester/The Christie NHS Foundation Trust, Manchester, UK; ${ }^{7}$ Department of Hepatopancreatobiliary Surgery, Central Manchester NHS Foundation Trust, Manchester, UK; ${ }^{8}$ Institute of Cancer Sciences, University of Manchester, Manchester, UK; ${ }^{9}$ Hepatobiliary Unit, Manchester Royal Infirmary, Manchester, UK; ${ }^{10}$ Specialised Cancer Services, Sheffield Teaching Hospitals NHS Foundation Trust, Sheffield, UK; ${ }^{11}$ Hepatobiliary Surgery, Hampshire Hospitals NHS Foundation Trust, Basingstoke, UK; ${ }^{12}$ Department of Medical Oncology, Hampshire Hospitals NHS Foundation Trust, Basingstoke, UK; ${ }^{13}$ University Hospital Southampton NHS Foundation Trust, Southampton, UK; ${ }^{14}$ Bournemouth University, Bournemouth, UK; ${ }^{15}$ Poole Hospital, Poole, UK; ${ }^{16}$ Department of Clinical Surgery, The University of Edinburgh, Edinburgh, UK; ${ }^{17}$ Department of Medicine, Gastrointestinal and Lymphoma Units, The Royal Marsden Hospital NHS Foundation Trust, London, UK; ${ }^{18}$ Department of Oncology, University of Oxford, Oxford, UK and ${ }^{19}$ University College London Cancer Institute, London, UK

Background: The addition of cetuximab (CTX) to perioperative chemotherapy (CT) for operable colorectal liver metastases resulted in a shorter progression-free survival. Details of disease progression are described to further inform the primary study outcome.

Methods: A total of 257 KRAS wild-type patients were randomised to CT alone or CT with CTX. Data regarding sites and treatment of progressive disease were obtained for the 109 (CT $n=48$, CT and CTX $n=61$ ) patients with progressive disease at the cut-off date for analysis of November 2012.

Results: The liver was the most frequent site of progression (CT 67\% (32/48); CT and CTX 66\% (40/61)). A higher proportion of patients in the CT and group had multiple sites of progressive disease (CT 8\%, 4/48; CT and CTX 23\%, 14/61 P=0.04). Further treatment for progressive disease is known for 84 patients of whom 69 received further CT, most frequently irinotecan based. Twenty-two patients, 11 in each arm, received CTX as a further line agent.

Conclusions: Both the distribution of progressive disease and further treatment are as expected for such a cohort. The pattern of disease progression seen is consistent with failure of systemic micrometastatic disease control rather than failure of local disease control following liver surgery.

*Correspondence: Dr S Pugh; E-mail S.Pugh@soton.ac.uk

Received 19 February 2016; revised 2 June 2016; accepted 13 June 2016; published online 19 July 2016

(c) 2016 Cancer Research UK. All rights reserved 0007 - 0920/16 
Surgical resection of colorectal liver metastasis (CRLM) is feasible in $10-20 \%$ of patients presenting with liver-only disease and confers a five-year survival of $35-40 \%$ (Kanas et al, 2012). Following resection disease progression is a challenge, occurring in $75 \%$ of patients (Nordlinger et al, 1996) of which half of the recurrences are in the liver (Lorenz et al, 1998; Giacchetti et al, 1999; Andre et al, 2004). Perioperative chemotherapy (CT) can reduce the risk of relapse (Nordlinger et al, 2008) as well as obviating surgery in those who progress rapidly because of poor biology, and has become standard of care in many centres. The New EPOC study sought to assess the benefit of adding cetuximab (CTX), an antibody to the epidermal growth factor receptor, to standard perioperative CT for patients with operable CRLM. Unexpectedly, the addition of CTX resulted in a significantly shorter progressionfree survival (Primrose et al, 2014).

Following surgery for CRLM the most common site of first treatment failure is the liver with the lung being second (Nordlinger et al, 2008; de Jong et al, 2009). Data suggest that the pattern of recurrence is relevant to outcome with lung only recurrence possibly favouring a better prognosis (Govaert et al, 2014). In the context of significant progression-free intervals, selected patients can expect improved survival with further lung and liver resection (Luo et al, 2014). For those unsuitable for additional surgery, further systemic treatment offers good disease control, reflected in the favourable long-term survival for patients presenting with CRLM (Nordlinger et al, 2013).

We have examined the pattern of treatment failure in the New EPOC study to determine whether it can inform the unexpected study outcome. Potential differences in post-progression therapy may inform an important secondary end point such as overall survival.

\section{MATERIALS AND METHODS}

Study design, treatments and objectives. The New EPOC study (ISRCTN 22944367) design, eligibility criteria and treatment regimens have been described previously (Primrose et al, 2014). This was a multi-centre prospective randomised open label phase III controlled trial. The study was approved by the South West Research Ethics Committee and all patients provided written informed consent. Patients with KRAS exon 2 wild-type resectable or suboptimally resectable colorectal liver metastases were randomised $1: 1$ to receive CT with or without CTX before and after liver resection. The primary objective was to determine a difference in progression-free survival between the treatment groups. The trial was closed to recruitment on 1 November 2012 when protocol-defined futility criteria were met. The focus of the present analysis is to ascertain detailed data regarding the patients with progressive disease.

Data collection. Gender, age, site of primary disease, lymph node involvement, serum CEA level and dates of progression and death had already been obtained as part of New EPOC. For the 109 patients $(\mathrm{CT}$ alone group $=48$, CT plus CTX group $=61$ ) with progressive disease at the cut-off date for analysis of 1 November 2012, additional data regarding first site(s) of progressive disease and treatments undertaken for progressive disease were obtained using case report forms. One patient, who was previously reported as having progressed before the data cut-off, has since been confirmed as not having progressive disease. An additional 13 patients (CT alone group $n=8$, CT plus CTX group $n=5$ ) died but had not progressed.

Post-progression survival was defined as the time from date of progression to death. Patients still alive were censored at their date of last follow-up or 1 November 2012, whichever was earlier, so as not to release data that are at present immature but that will contribute to a final analysis of the trial in the future.

Statistical analysis. The comparison of post-progression survival between the treatment groups was done with Cox proportionalhazards regression and Kaplan-Meier curves. All analyses were done on a modified intention-to-treat basis, including all patients with known KRAS exon 2 wild-type genotype who had confirmed progressive disease at the cut-off date for analysis of 1 November 2012. Only the analyses on further lines of CT were pre-defined. SAS (version 9.2 or above, SAS Institute Inc., Cary, NC, USA) and STATA (version 11 or above, StataCorp LP, College Station, TX, USA) were used for all analyses.

\section{RESULTS}

The clinico-pathologic features of the 110 patients with progressive disease identified before the cut-off for analysis of 1 November 2012 are shown in table one as previously described (Primrose et al, 2014). The baseline and clinico-pathologic characteristics of the patients with progressive disease were similar between the groups (Table 1).

Of the 109 patients with progression events, the majority occurred after surgery (CT group 27\% (13/48) vs 73\% (35/48), CT and CTX group 25\% (15/61) vs 75\% (46/61); Table 2). Approximately half of all progression events involved the liver only (CT 60\% (29/48), CTX group 49\% (30/61)). When this analysis is restricted to those patients with post- rather than pre-operative progression, the same trend is apparent (CT 54\% (19/35), CTX $48 \%(22 / 46))$. Other single sites of progressive disease were similarly well balanced between the two groups of the trial, although a higher proportion of patients in the CTX group had multiple sites of progressive disease (CT 8\%, 4/48; CTX 23\%, $14 / 61$, difference $15 \% 95 \%$ CI $2.0 \%-28.1 \% P=0.04)$.

Over three quarters of patients (84/109) were reported to have undergone further treatment(s) for progressive disease (CT $75 \%$ (36/48); CTX 79\% (48/61)). Of those the majority received further CT (CT 58\%, 28/48; CTX 67\%, 41/61), however, 31\% (15/48) in the CT group and 23\% (14/61) in the CTX group underwent surgical treatment of progressive disease with curative intent (Table 3 ). Four patients $(4 / 48)$ in the CT group and six patients $(6 / 61)$ patients in the CTX group received ablative therapies for progressive disease in the liver, lung or both. Radiotherapy was used to treat progressive disease in $6 \%(3 / 48)$ of patients in the CT group and 7\% (4/61) in the CTX group. Twenty-seven percent

\begin{tabular}{|c|c|c|}
\hline Characteristic & $\begin{array}{l}\text { Chemotherapy } \\
\text { alone }(n=48)\end{array}$ & $\begin{array}{l}\text { Chemotherapy }+ \\
\text { cetuximab }(n=61)\end{array}$ \\
\hline $\begin{array}{l}\text { Median age at } \\
\text { randomisation (years) }\end{array}$ & 65 & 64 \\
\hline $\begin{array}{l}\text { Gender } \\
\text { Male } \\
\text { Female }\end{array}$ & $\begin{array}{l}29(60 \%) \\
19(40 \%)\end{array}$ & $\begin{array}{l}42(69 \%) \\
19(31 \%)\end{array}$ \\
\hline $\begin{array}{l}\text { Number of metastases } \\
1 \text { metastasis } \\
>1 \text { metastases }\end{array}$ & $\begin{array}{l}21(44 \%) \\
27(56 \%)\end{array}$ & $\begin{array}{l}29(48 \%) \\
31(51 \%)\end{array}$ \\
\hline Missing & 0 & $1(2 \%)$ \\
\hline $\begin{array}{l}\text { Presentation of disease } \\
\text { Synchronous metastases } \\
\text { Non-synchronous metastases }\end{array}$ & $\begin{array}{l}27(56 \%) \\
21(44 \%)\end{array}$ & $\begin{array}{l}33(54 \%) \\
28(46 \%)\end{array}$ \\
\hline $\begin{array}{l}\text { Treatment regimen } \\
\text { CAPOX } \\
\text { OxMdG } \\
\text { IrMdG }\end{array}$ & $\begin{array}{r}14(29 \%) \\
28(58 \%) \\
6(13 \%)\end{array}$ & $\begin{array}{r}17(28 \%) \\
38(62 \%) \\
6(10 \%)\end{array}$ \\
\hline
\end{tabular}


Table 2. Site(s) of first progressive disease

\begin{tabular}{|l|c|c|}
\hline Site & $\begin{array}{c}\text { Chemotherapy } \\
\text { alone }(\mathbf{n = 4 8 )}\end{array}$ & $\begin{array}{c}\text { Chemotherapy }+ \\
\text { cetuximab }(\boldsymbol{n}=\mathbf{6 1})\end{array}$ \\
\hline Preoperative progression & 13 & 15 \\
\hline Liver only & $10(77 \%)$ & $8(53 \%)$ \\
Lung only & $1(8 \%)$ & 0 \\
Locoregional only & 0 & $1(7 \%)$ \\
Peritoneal only & $1(8 \%)$ & $1(7 \%)$ \\
Nodal & 0 & 0 \\
Multi-site & 0 & $5(33 \%)$ \\
Unknown & $1(8 \%)$ & 0 \\
\hline Postoperative progression & 35 & 46 \\
\hline Liver only & $19(54 \%)$ & $22(47 \%)$ \\
Lung only & $8(23 \%)$ & $8(17 \%)$ \\
Locoregional only & $1(3 \%)$ & $3(7 \%)$ \\
Peritoneal only & $2(6 \%)$ & 0 \\
Nodal & $1(3 \%)$ & $4(9 \%)$ \\
Multi-site & $4(11 \%)$ & $9(20 \%)$ \\
\hline a ${ }_{\text {Patient withdrew from trial at the time of progression. }}$ \\
\hline \multicolumn{2}{|c}{}
\end{tabular}

Table 3. Treatment of progressive disease with curative intent

\begin{tabular}{|c|c|c|}
\hline Site & $\begin{array}{l}\text { Chemotherapy } \\
\text { alone }(n=48)\end{array}$ & $\begin{array}{l}\text { Chemotherapy }+ \\
\text { cetuximab }(n=61)\end{array}$ \\
\hline Surgery & 15 (31\%) & $14(23 \%)$ \\
\hline Liver resection & $11(23 \%)^{a}$ & $8(13 \%)^{b}$ \\
\hline Lung resection & $3(6 \%)$ & $3(5 \%)$ \\
\hline Liver and lung resection & $1(2 \%)$ & $2(3 \%)$ \\
\hline Multivisceral resection & 0 & $1(2 \%)$ \\
\hline Ablation & $4(8 \%)$ & $5(8 \%)$ \\
\hline Liver ablation & $3(6 \%)$ & $2(3 \%)$ \\
\hline Lung ablation & $1(2 \%)$ & $1(2 \%)$ \\
\hline Liver and lung ablation & 0 & $2(3 \%)$ \\
\hline \multicolumn{3}{|c|}{$\begin{array}{l}{ }^{a_{\text {Five }}} \text { of these liver resections were performed for preoperative progression and as such } \\
\text { were the first liver resection these patients underwent. } \\
b_{\text {Two of these liver resections were for preoperative progression and as such were the first }} \\
\text { liver resection these patients underwent. }\end{array}$} \\
\hline
\end{tabular}

(13/48) in the CT group and 41\% (25/61) in the CTX group received CT alone as treatment for progressive disease.

Data were received on 69 patients (16 who had pre-operative progression and 53 who had post-operative progression) that received further CT for progressive disease (Table 4). The majority of second-line therapy given was irinotecan-based without any additional biological therapy. Twenty-two were given CTX as a further line treatment: 11 following CT and 11 following CTX. Four patients received CTX as a second line treatment for progressive disease having had CT plus CTX as part of the trial. Anti-vascular endothelial growth factor therapy was given as a treatment for progressive disease to 26 patients: 7 in the CT group and 19 in the CTX group.

Median follow-up post progression was 14.5 months (95\% CI 5.4-19.6) in the CT alone group and 14.2 months (95\% CI 6.319.5 ) in the CT plus CTX group. The median post-progression survival was 18.7 months (95\% CI 13.1-not reached; Figure 1) in the CT group compared with 15.9 months (95\% CI 8.6-26.1) in the CTX group (HR 1.69, 95\% CI 0.86-3.34 P=0.130). When this analysis was restricted to those patients that underwent a R0 resection of the liver as part of the trial (29 in the CT group, 34 in the CTX group), the median post-progression survival was 29.0 months (95\% CI 16.5-not reached) in the CT group compared with 19.9 months (95\%CI 13.2-not reached) in the CTX group (HR 2.07 95\% CI 0.70-6.09 $P=0.187)$.
Table 4. Further lines of chemotherapy for progressive disease

\begin{tabular}{|l|c|c|}
\hline Treatment & $\begin{array}{c}\text { Chemotherapy } \\
(\mathbf{n = 4 8 )}\end{array}$ & $\begin{array}{c}\text { Chemotherapy }+ \\
\text { cetuximab }(\mathbf{n = 6 1 )}\end{array}$ \\
\hline Type of 2nd line treatment & 27 & 41 \\
\hline Oxaliplatin based & $5(19 \%)$ & $5(12 \%)$ \\
Irinotecan based & $9(33 \%)$ & $17(41 \%)$ \\
Fluropyrimidine only & $2(7 \%)$ & $2(5 \%)$ \\
Cetuximab based & $8(30 \%)$ & $4(10 \%)$ \\
Bevacizumab based & $3(11 \%)$ & $12(29 \%)$ \\
Aflibercept based & 0 & $1(2 \%)$ \\
Other & 0 & 0 \\
\hline Type of 3rd line treatment & 16 & 20 \\
\hline Oxaliplatin based & $3(19 \%)$ & $4(20 \%)$ \\
Irinotecan based & $3(19 \%)$ & $3(15 \%)$ \\
Fluropyrimidine only & $2(13 \%)$ & $1(5 \%)$ \\
Cetuximab based & $2(13 \%)$ & $4(20 \%)$ \\
Bevacizumab based & $3(19 \%)$ & $4(20 \%)$ \\
Aflibercept based & $1(6 \%)$ & $1(5 \%)$ \\
Other & $1(6 \%)$ & $3(15 \%)$ \\
Selective internal & $1(6 \%)$ & 0 \\
radiation therapy & & \\
\hline Type of 4th line treatment & 4 & 7 \\
\hline Oxaliplatin based & 0 & $1(14 \%)$ \\
Irinotecan based & $1(25 \%)$ & 0 \\
Fluropyrimidine only & 0 & $1(14 \%)$ \\
Cetuximab based & $1(25 \%)$ & $3(43 \%)$ \\
Bevacizumab based & 0 & $1(14 \%)$ \\
Aflibercept based & 0 & 0 \\
Other & $2(50 \%)$ & $1(14 \%)$ \\
\hline Data on further lines of chemotherapy received between October 2013 and May 2014. \\
Percentages are based on the number within each type of treatment line, as shown in the \\
'Type of xth line treatment'. & & \\
\hline
\end{tabular}

Time to death from disease progression

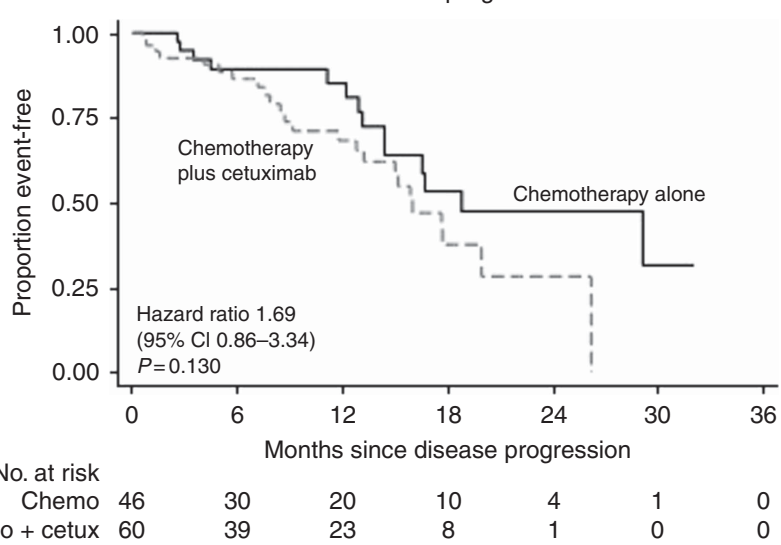

Figure 1. Kaplan-Meier curve of post-progression survival by treatment group.

A total of 38 patients have had surgery or ablation with curative intent for progressive disease. The post-progression survival of these individuals was compared with those who did not receive surgery or ablative therapy with curative intent for progressive disease. Median follow-up post progression was 12.8 months (95\% CI 5.4-19.2) in the surgery/ablation with curative intent for progressive disease group and 14.5 months (95\% CI 6.0-24.0) in the group with progressive disease not treated with curative intent. The median post-progression survival was not reached in the surgically/ablation treated group (lower limit of 95\% CI 26.1 months; Figure 2) compared with 14.3 months (95\% CI 8.4-17.6) in the group not treated with curative intent for progressive disease (HR 17.42, 95\% CI 4.14-73.25, $P<0.001$ ). 
Time to death from disease progression

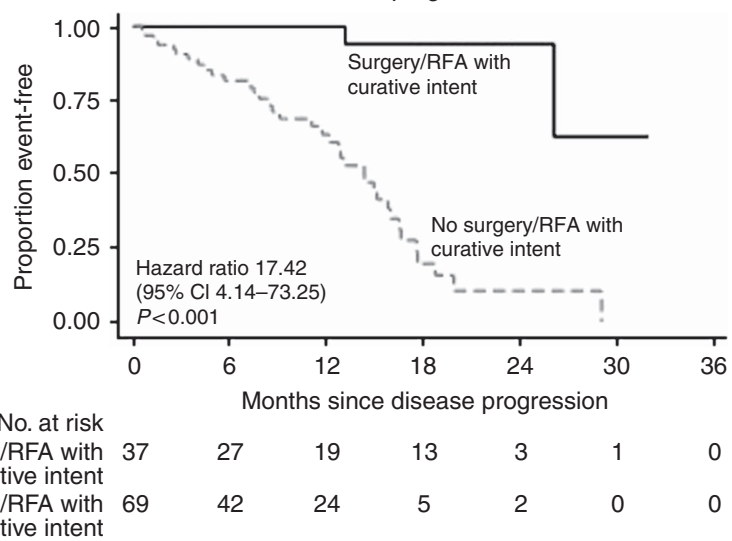

Figure 2. Kaplan-Meier curve of post-progression survival according to whether treatment of progressive disease was undertaken with curative or palliative intent.

\section{DISCUSSION}

This analysis demonstrates that the pattern of progression and subsequent treatment for patients do not differ substantially between the arms of the New EPOC study. There is one notable difference, a significantly higher proportion of multi-site recurrences in the CTX group, although the numbers are modest. In both arms of the study, the liver was the most frequent first site of failure. This pattern of disease progression is much the same as that observed in other studies including the original EPOC study (Nordlinger et al, 2008; de Jong et al, 2009).

The incidence of progressive disease in the liver was comparable between the two groups of the trial. This refutes the contention that inadequate surgery or differential use of ablation was responsible for the primary study outcome (Nordlinger et al, 2015; Primrose et al, 2015). It also allays concerns regarding the possibility of differential imaging being performed before trial entry. All patients were managed in high-volume liver centres and while the trial protocol only mandated computed tomography, the majority will have had additional imaging performed. As the randomisation is stratified by centre (hence MDT) bias is not possible. Indeed the large majority of progression events were post surgery and the greater proportion of multi-site progressions in the CT plus CTX group is more in keeping with a failure of systemic disease control.

The majority of patients with disease progression received additional off-trial treatments. The choice of further systemic therapy is as expected for such a cohort and reasonably similar in both groups. A number of patients received antibody therapies in the second or subsequent lines of treatment which is in keeping with their availability under the Cancer Drug Fund (introduced in the UK in 2011). Those treated with CT alone as part of the trial often received CTX post progression and indeed some that received it on trial also received it following progression. This pattern of post-progression treatment is consistent with standard practice in the UK.

Progression-free survival is widely accepted as a surrogate for overall survival in clinical trials of colorectal cancer (Giessen et al, 2013). It is however important to distinguish between curative and palliative intent. For liver only progression, one-third of those that progressed during the neoadjuvant phase of treatment went onto have a potentially curative liver resection and a similar proportion that progressed postoperatively underwent a further liver resection. These data are in line with a published series suggesting that approximately one-third of recurrences in the liver can be offered repeat hepatectomy (Jones et al, 2012).
Overall this analysis demonstrates that a quarter of patients went onto have further surgery with curative intent, predominantly lung and/or liver resections. This was balanced between the groups. Repeat liver surgery has been shown to be associated with favourable survival outcomes (Petrowsky et al, 2002; Lam et al, 2013; Luo et al, 2014), and indeed the post-progression survival for the cohort treated with curative intent looks most favourable, although it is noteworthy that the period of follow-up available is presently short. The relatively short follow-up (consequent in part on premature study cessation) restricts the ability of these data to inform whether the detrimental effect of CTX persists beyond relapse and a final analysis will obviate these issues.

In summary, the present study demonstrates that the pattern of failure associated with the addition of CTX to surgery and routine CT for operable colorectal liver metastases is as expected for such a cohort. The slightly higher proportion of multi-site recurrence in the CT and CTX group is the only notable difference. The pattern of disease progression seen is strongly suggestive of a systemic failure consistent with micrometastatic disease rather than local failure of disease control at the site of resection.

\section{ACKNOWLEDGEMENTS}

The New EPOC study was funded by Cancer Research UK and supported by the National Cancer Research Institute via the National Cancer Research Network. This study was also supported by a medical grant from Merck KGaA, Darmstadt, Germany. JB is funded partly from the National Institute for Health Research Biomedical Research Centres at University College London Hospitals. DC is supported by the National Institute for Health Research Biomedical Research Centre based at the Royal Marsden Hospital and the Institute of Cancer Research (both in London, UK).

\section{CONFLICT OF INTEREST}

SF declared a consulting or advisory role to Merck. JV declared honoraria and travel/accommodation expenses from Merck. DO declared honoraria from Abbott and travel/accommodation expenses from Novartis and Angiodynamics. CR declared travel/ accommodation expenses from Roche, Merck and Amgen. TI declared receiving honoraria from Roche and Celgene, a consulting or advisory role to Roche and Servier, and travel/accommodation expenses from Amgen and Bayer. OJG declared honoraria from Johnson and Johnson (Ethicon). DC declared receiving honoraria/ research funding from Amgen, AstraZeneca, Bayer, Celgene, Medimmune, Merrimack, Merck Serono, and Sanofi. TM declared honoraria from Vertex, a consulting or advisory Role to Sanofi and research funding from AstraZeneca (Inst) and Merck Serono (Inst). JB declared receiving honoraria from Merck and Roche, attending a speakers' bureau for Merck Serono and receiving travel/accommodation expenses from Merck. The remaining authors declare no conflict of interest.

\section{REFERENCES}

Andre T, Boni C, Mounedji-Boudiaf L, Navarro M, Tabernero J, Hickish T, Topham C, Zaninelli M, Clingan P, Bridgewater J, Tabah-Fisch I, de Gramont A. Multicenter International Study of Oxaliplatin/5-Fluorouracil/ Leucovorin in the Adjuvant Treatment of Colon Cancer I (2004)

Oxaliplatin, fluorouracil, and leucovorin as adjuvant treatment for colon cancer. N Engl J Med 350(23): 2343-2351.

de Jong MC, Pulitano C, Ribero D, Strub J, Mentha G, Schulick RD, Choti MA, Aldrighetti L, Capussotti L, Pawlik TM (2009) Rates and 
patterns of recurrence following curative intent surgery for colorectal liver metastasis: an international multi-institutional analysis of 1669 patients. Ann Surg 250(3): 440-448.

Giacchetti S, Itzhaki M, Gruia G, Adam R, Zidani R, Kunstlinger F, Brienza S, Alafaci E, Bertheault-Cvitkovic F, Jasmin C, Reynes M, Bismuth H, Misset JL, Levi F (1999) Long-term survival of patients with unresectable colorectal cancer liver metastases following infusional chemotherapy with 5fluorouracil, leucovorin, oxaliplatin and surgery. Ann Oncol 10(6): 663-669.

Giessen C, Laubender RP, Ankerst DP, Stintzing S, Modest DP, Mansmann U, Heinemann V (2013) Progression-free survival as a surrogate endpoint for median overall survival in metastatic colorectal cancer: literature-based analysis from 50 randomized first-line trials. Clin Cancer Res 19(1): 225-235.

Govaert KM, van Kessel CS, Steller EJ, Emmink BL, Molenaar IQ, Kranenburg O, van Hillegersberg R, Borel Rinkes IH (2014) Recurrence location after resection of colorectal liver metastases influences prognosis. J Gastrointest Surg 18(5): 952-960.

Jones NB, McNally ME, Malhotra L, Abdel-Misih S, Martin EW, Bloomston M, Schmidt CR (2012) Repeat hepatectomy for metastatic colorectal cancer is safe but marginally effective. Ann Surg Oncol 19(7): 2224-2229.

Kanas GP, Taylor A, Primrose JN, Langeberg WJ, Kelsh MA, Mowat FS, Alexander DD, Choti MA, Poston G (2012) Survival after liver resection in metastatic colorectal cancer: review and meta-analysis of prognostic factors. Clin Epidemiol 4: 283-301.

Lam VW, Pang T, Laurence JM, Johnston E, Hollands MJ, Pleass HC, Richardson AJ (2013) A systematic review of repeat hepatectomy for recurrent colorectal liver metastases. J Gastrointest Surg 17(7): 1312-1321.

Lorenz M, Muller HH, Schramm H, Gassel HJ, Rau HG, Ridwelski K, Hauss J, Stieger R, Jauch KW, Bechstein WO, Encke A (1998) Randomized trial of surgery versus surgery followed by adjuvant hepatic arterial infusion with 5-fluorouracil and folinic acid for liver metastases of colorectal cancer. German Cooperative on Liver Metastases (Arbeitsgruppe Lebermetastasen). Ann Surg 228(6): 756-762.

Luo LX, Yu ZY, Huang JW, Wu H (2014) Selecting patients for a second hepatectomy for colorectal metastases: an systemic review and metaanalysis. Eur J Surg Oncol 40(9): 1036-1048.

Nordlinger B, Guiguet M, Vaillant JC, Balladur P, Boudjema K, Bachellier P, Jaeck D (1996) Surgical resection of colorectal carcinoma metastases to the liver. A prognostic scoring system to improve case selection, based on 1568 patients. Association Francaise de Chirurgie. Cancer 77(7): 1254-1262.

Nordlinger B, Poston GJ, Goldberg RM (2015) Should the results of the new EPOC trial change practice in the management of patients with resectable metastatic colorectal cancer confined to the liver? J Clin Oncol 33(3): 241-243.

Nordlinger B, Sorbye H, Glimelius B, Poston GJ, Schlag PM, Rougier P, Bechstein WO, Primrose JN, Walpole ET, Finch-Jones M, Jaeck D, Mirza D, Parks RW, Collette L, Praet M, Bethe U, Van Cutsem E, Scheithauer W, Gruenberger T (2008) Perioperative chemotherapy with FOLFOX4 and surgery versus surgery alone for resectable liver metastases from colorectal cancer (EORTC Intergroup trial 40983): a randomised controlled trial. Lancet 371(9617): 1007-1016.

Nordlinger B, Sorbye H, Glimelius B, Poston GJ, Schlag PM, Rougier P, Bechstein WO, Primrose JN, Walpole ET, Finch-Jones M, Jaeck D, Mirza D, Parks RW, Mauer M, Tanis E, Van Cutsem E, Scheithauer W, Gruenberger T. Group EG-ITC, Cancer Research UK, Arbeitsgruppe Lebermetastasen und-tumoren in der Chirurgischen Arbeitsgemeinschaft O, Australasian Gastro-Intestinal Trials G, Federation Francophone de Cancerologie D (2013) Perioperative FOLFOX4 chemotherapy and surgery versus surgery alone for resectable liver metastases from colorectal cancer (EORTC 40983): long-term results of a randomised, controlled, phase 3 trial. Lancet Oncol 14(12): 1208-1215.

Petrowsky H, Gonen M, Jarnagin W, Lorenz M, DeMatteo R, Heinrich S, Encke A, Blumgart L, Fong Y (2002) Second liver resections are safe and effective treatment for recurrent hepatic metastases from colorectal cancer: a bi-institutional analysis. Ann Surg 235(6): 863-871.

Primrose J, Falk S, Finch-Jones M, Valle J, O’Reilly D, Siriwardena A, Hornbuckle J, Peterson M, Rees M, Iveson T, Hickish T, Butler R, Stanton L, Dixon E, Little L, Bowers M, Pugh S, Garden OJ, Cunningham D, Maughan T, Bridgewater J (2014) Systemic chemotherapy with or without cetuximab in patients with resectable colorectal liver metastasis: the New EPOC randomised controlled trial. Lancet Oncol 15(6): 601-611.

Primrose JN, Cunningham D, Garden OJ, Maughan TS, Pugh SA, Stanton L, Falk SJ, Rees M, Finch-Jones M, Valle JW, O'Reilly D, Hornbuckle J, Hickish T, Bridgewater JA (2015) Cetuximab is contraindicated in the perioperative treatment of colorectal liver metastases. J Clin Oncol 33(21): 2405-2406.

This work is published under the standard license to publish agreement. After 12 months the work will become freely available and the license terms will switch to a Creative Commons AttributionNonCommercial-Share Alike 4.0 Unported License. 